OPEN ACCESS

Edited by:

Jens Geginat,

Istituto Nazionale Genetica Molecolare

(INGM), Italy

Reviewed by:

Elisabeth Gulowsen Celius,

Oslo University Hospital, Norway

Michael Joseph Olek,

Touro University Nevada,

United States

*Correspondence:

Florian Deisenhammer

florian.deisenhammer@tirol-kliniken.at

Specialty section:

This article was submitted to

Multiple Sclerosis and

Neuroimmunology,

a section of the journal

Frontiers in Immunology

Received: 22 November 2018 Accepted: 18 March 2019

Published: 12 April 2019

Citation:

Deisenhammer F, Zetterberg $\mathrm{H}$, Fitzner B and ZettI UK (2019) The

Cerebrospinal Fluid in Multiple

Sclerosis. Front. Immunol. 10:726.

doi: 10.3389/fimmu.2019.00726

\section{The Cerebrospinal Fluid in Multiple Sclerosis}

\author{
Florian Deisenhammer ${ }^{1 *}$, Henrik Zetterberg ${ }^{2,3,4,5}$, Brit Fitzner $^{6}$ and Uwe K. ZettI ${ }^{6}$ \\ ${ }^{1}$ Department of Neurology, Innsbruck Medical University, Innsbruck, Austria, ${ }^{2}$ Department of Psychiatry and Neurochemistry, \\ Institute of Neuroscience and Physiology, The Sahlgrenska Academy at the University of Gothenburg, Mölndal, Sweden, \\ ${ }^{3}$ Clinical Neurochemistry Laboratory, Sahlgrenska University Hospital, Mölndal, Sweden, ${ }^{4}$ Department of Neurodegenerative \\ Disease, UCL Institute of Neurology, London, United Kingdom, ${ }^{5}$ The Fluid Biomarker Laboratory, UK Dementia Research \\ Institute at UCL, London, United Kingdom, ${ }^{6}$ Division of Neuroimmunology, Department of Neurology, University Medicine \\ Rostock, Rostock, Germany
}

Investigation of cerebrospinal fluid (CSF) in the diagnostic work-up in suspected multiple sclerosis (MS) patients has regained attention in the latest version of the diagnostic criteria due to its good diagnostic accuracy and increasing issues with misdiagnosis of MS based on over interpretation of neuroimaging results. The hallmark of MS-specific changes in CSF is the detection of oligoclonal bands (OCB) which occur in the vast majority of MS patients. Lack of OCB has a very high negative predictive value indicating a red flag during the diagnostic work-up, and alternative diagnoses should be considered in such patients. Additional molecules of CSF can help to support the diagnosis of MS, improve the differential diagnosis of MS subtypes and predict the course of the disease, thus selecting the optimal therapy for each patient.

Keywords: CSF (cerebrospinal fluid), biomarker, multiple sclerosis, oligoclonal band (OCB), neurofilament light (NfL)

\section{INTRODUCTION}

Oligoclonal bands (OCB) of the cerebrospinal fluid (CSF) have been important in the diagnosis of multiple sclerosis (MS) for many years. The further search for biomarkers is of great importance in order to improve the diagnosis and therapy of MS. This review is divided into 2 parts. The first part focuses on OCB as diagnostic biomarker for MS and briefly describes other diagnostic markers such as aquaporin4 (AQP4) and biomarkers that are about to enter clinical routine, such as antimyelin oligodendrocyte glycoprotein (MOG). The second part is about CSF molecules, which have been described in research as potential biomarkers.

\section{PART I: THE CLINICAL LABORATORY}

\section{Cerebrospinal Fluid-General Considerations}

Whenever investigations are required either to make or rule out a particular disease, it is of utmost importance to know what one would normally expect from such an investigation, i.e., to have access to normal or reference values. This goes of course also for clinical chemistry tests performed in CSF. As a prerequisite for making reference values global and assay-independent, it is important to standardize the field through the certification of reference methods and materials that can be used as external calibrators for assay manufacturers. It is also important to establish external quality control programmes to make sure laboratories are both accurate and precise. Internal stability of the measurements also has to be monitored using internal control samples each time a test is performed. 
It is surprising how little progress has been made in the field of reference values for CSF analytes since the first systematic assessment of CSF normal values by Meritt and Fremont-Smith (1). For one of the most basic CSF variables, i.e., total protein and albumin, normal values based on modern quality standards have been evaluated and published only recently (2). Most labs adopt historical reference values without validating their own (3). Even if normal values have been established in some labs the methods of evaluation suffer from methodological shortcomings, such as selection bias, poor definition of normal cohorts, and statistical errors (2). Because upper reference limits for total CSF protein are mostly too low it has been estimated that approximately in $15 \%$ of normal CSFs total protein values are falsely reported as pathologically elevated. Similar issues have been found with CSF glucose measurements and formulas for intrathecal immunoglobulin synthesis $(4,5)$. Glucose measurements must be done in CSF and serum simultaneously and a ratio needs to be calculated. The glucose ratio cut-off values depend on serum glucose levels because the transporter systems across the blood-brain-barrier (BBB) have limited capacities. This fact is often not considered by CSF labs. For intrathecal synthesis of immunoglobulins it is well-known that the widespread Reiberformula overestimates particularly intrathecal $\operatorname{IgM}$ and $\operatorname{IgA}$ synthesis rates $(4,6)$.

\section{How Is All This Related to the Diagnosis of MS?}

Because the etiology and specific pathogenesis of MS are unknown, there is no specific test, be it lab-based or otherwise, available. In diseases with a known cause, e.g., infections, a specific test detecting the infectious agent or antibodies against it is most frequently available. Even in entities in which the cause is not fully elucidated but the pathomechanism is evident, such as autoimmune encephalitides, a specific test detecting the autoantibody can be used to make the diagnosis (7). In MS there is no such specific test available which is why one needs to rely on "circumstantial evidence." The diagnosis is based on typical, yet not limited to, clinical findings, magnetic resonance imaging (MRI), and CSF as well as other investigations (8). Doctors are well-advised to use all these tools in order to optimize the diagnostic accuracy.

In the past two decades the diagnostic criteria for MS have been updated 4 times (8-11). Starting with the revision in 2001 (9) CSF was less and less required to confirm the diagnosis in the subsequent updates until 2010 (11). As some authors suspected (12), ignorance of diagnostic tools might

\footnotetext{
Abbreviations: AQP4, aquaporin 4; C1inh, Complement component 1-inhibitor; CAM, cell adhesion molecule; CDMS, clinical definite MS; CSF, cerebrospinal fluid; CHI3L, protein chitinase 3-like; CIS, clinically isolated syndrome; CXCL, chemokine (c-x-c motif) ligand; GFAP, glial fibrillary acidic protein; HC, healthy control; IL, interleukin; JCV, John Cunningham virus; MOG, myelin oligodendrocyte glycoprotein; MS, multiple sclerosis; Nf, neurofilament; $\mathrm{NfH}$, Nf heavy; NfL, Nf light; NIND, non-inflammatory neurological disease; NMOSD, neuromyelitis optica spectrum disorders; OCB, oligoclonal bands; OCGB, oligoclonal immunoglobulin $\mathrm{G}$ bands; $\mathrm{OCMB}$, oligoclonal immunoglobulin $\mathrm{M}$ bands; OIND, other inflammatory neurological disease; OND, other neurological disease; RRMS, relapsing-remitting MS; sCD, soluble cluster of differentiation; sICAM, soluble intercellular CAM; sVCAM, soluble vascular CAM.
}

have led to insufficient diagnostic performance, in that the rate of MS misdiagnosis increased, even though there is no formal proof that this phenomenon occurred due to the decrease in CSF examinations (13). Mostly, misdiagnosis was due to overinterpretation and misinterpretation of MRI findings (13). Moreover, the true diagnoses were most often migraine, fibromyalgia, unspecific symptoms, or psychogenic disorders (14). In these diagnoses, CSF findings are usually normal, including markers of intrathecal immune-activation such as quantitative elevation of immunoglobulins (e.g., IgG-index) or detection of OCB. One must keep in mind that the negative predictive value of $\mathrm{OCB}$ in neurological patients who had undergone LP was 90\% (15), and even in patients with clinically isolated syndromes (CIS-a clinical syndrome highly suspicious of a first manifestation of MS) the negative predictive value of OCB was $88 \%$ (16). So, the lack of OCB in CSF must be considered a red flag in the differential diagnostic workup. In this context, it should be remembered that the first reported case of natalizumab-associated progressive multifocal leukoencephalopathy occurred in a very likely misdiagnosed patient, who had no detectable OCB in CSF in two consecutive occasions (17). In fact, the vast majority of misdiagnosed patients get actually treated with MS drugs (14).

\section{Oligoclonal Bands in CSF-How Likely Is It MS?}

It is well-known that OCB in CSF are not exclusively found in MS. OCB are thought to indicate chronic immune-activation in the CNS and therefore, can be found in a variety of chronic inflammatory diseases. The positive predictive value (PPV) of OCB for MS depends on the control or reference populationan inherent issue with PPV-and on the integration of other CSF findings, such as cell counts or albumin/protein concentrations. E.g., in neuroborreliosis, OCB are frequently encountered, in contrast to MS, however, total protein concentration and CSF cell counts are substantially higher (18). Several authors found OCB in CSF highly sensitive and specific for MS (19), which is likely due to the fact that other diseases with OCB in CSF occur relatively seldom. However, when inflammatory diseases are particularly considered, the specificity of OCB for MS drops substantially from 94 to $61 \%$, as shown in a meta-analysis (20). This highlights again that the diagnostic tools for MS are not unidimensional.

Apart from MS, there is a long list of diagnoses with CSF OCBs reported: systemic lupus erythematosus, neurosyphilis, neurological paraneoplastic disorders, Behcet's disease neuroborreliosis, aseptic meningitis, neurosarcoidosis, HIV infection, cerebral tumors including lymphomas, Sjögren's syndrome, herpes encephalitis, Morvan syndrome, AntiNMDA and other autoimmune encephalitis, neurotuberculosis, anticardiolipin syndrome, HTLV myelopathy, prion disease, schistosomiasis, stiff-person syndrome, cerebral cysticercosis, GBS, CNS vasculitis (20). One must be careful however, in our experience running a clinical CSF lab for decades, we rarely detected OCB in solid cerebral tumors, prion disease, or GBS for instance. 


\section{Some Methodological Considerations}

As outlined above, a proper assessment of normal and reference values should be done in each CSF lab rather than adopting such values from the literature. Also, validation in case of inhouse developed assays must be done, or at least verification in case of commercially available, externally validated tests (21). One of the key CSF tests in query MS including differentials is the method of isoelectric focusing (IEF) (22). This method has been developed in the 70ies and has since then undergone several refinements. Today, IEF followed by IgG specific immunoblot is the recommended standard for detection of OCB (19). These guidelines developed some essential rules for CSF IgG detection as shown in Table 1. Importantly, intrathekal IgG synthesis can only be assessed if compared to serum. OCB in CSF can only be considered intrathecally synthesized if the bands selectively occur in CSF or if there are more bands in CSF than in serum, referred to as pattern 2 and 3 according to Freedman et al. (19). Depending on the IgG separation method, serum bands should be outnumbered by 1-3 bands in CSF (23). Identical bands in CSF and serum do not reflect pathological immunoglobulin synthesis in the CNS because the CSF bands have their origin in the systemic circulation. These findings are referred to as pattern 4 (identical oligoclonal) and 5 (identical monoclonal) according to Freedman et al. (19).

More recent developments regarding measurements of intrathecal immune activation include detection of free light chains (FLC). There are several reports that, particularly, kappa FLC are equally sensitive and specific for clonal expansion as detection of OCB in MS (24). The advantages of FLC measurements are its methodological simplicity and its objective read-out by instrumental measurements of concentrations rather than visual inspection of OCB. However, before general implementation of FLC detection or even replacement of IEF there is more work needed including independent confirmation by different labs and validation of specificity using broader ranges of control groups, particularly other inflammatory diseases.

A comprehensive overview regarding methodological aspects of CSF investigations in general can be found in recent publication (23).

TABLE 1 | Guidelines for lgG detection in CSF according to Freedman et al. (19).

CSF immunoglobulins must be separated by IEF

CSF immunoglobulins must not be separated by electrophoresis

CSF must not be concentrated

CSF immunoglobulins should be immunofixed/blotted

CSF and parallel serum must have similar amounts of immunoglobulin on the

same analytical run

IEF is always more sensitive than any quantitative formula for immunoglobulins in CSF/serum

To use "only" a quantitative formula is not recommended

Non-linear formulations are recommended over linear formulations

A quantitative formula may be more useful in treatment/prognosis than in diagnosis

Light chain immunofixation can extend the value of lgG immunofixation

\section{Expected CSF Changes in MS}

As MS is considered an inflammatory CNS disease with focal breakdown of the $\mathrm{BBB}$ one could expect markers of these events in CSF to be altered (Figure 1). Markers of these changes are CSF leukocyte counts as an indicator of inflammation (apart from elevated immunoglobulin levels), and total protein or albumin concentrations as an indicator of BBB disruption (23) (Table 2).

In about one half of MS patients CSF leukocyte counts will be elevated up to 50 cells per uL (22). Higher leukocyte counts occur in only $1-2 \%$ of patients and should give raise to consider alternative diagnoses, particularly infectious CNS diseases. On differential cell count lymphocytes dominate by far, accounting for more than $90 \%$ of cells, $90 \%$ of which are T-cells and $10 \%$ B-cells, which excludes lymphocyte subtyping as a distinctive feature of MS (25). The remainder is constituted by monocytes although other leukocyte types may be encountered such as plasma cells, macrophages, and very rarely granulocytes. Again, a substantial deviation from this pattern should be regarded as red flag regarding the correctness of the diagnosis.

Glucose CSF to serum ratios are normal in MS (26).

Total protein or albumin quotient is normal in the vast majority of patients $(22,27)$, which is in line with the very focal and transient BBB leakage in MS.

The hallmark of typical CSF changes in MS however, is the increased production of intrathekal immunoglobulins (28). To demonstrate this, the MS diagnostic guidelines refer to two different methods: first, quantitatively elevated IgG as shown by e.g., the IgG index, and second, detection of OCB by IEF (9). It must be kept in mind that any quantitative formula is less sensitive than OCB detection with elevated IgG being found in $\sim 60 \%$ of MS patients compared to $95 \%$ being OCB positive (i.e., diagnostic sensitivity) $(19,29)$. Even though it is not an MS specific test, the diagnostic specificity lies between 61 and 93\% depending on the reference group (30). The lowest specificity rates occur if other inflammatory CNS diseases are exclusively included in the comparator group. In a mixed reference population, one would expect the diagnostic specificity to be probably in the middle of these values, which means that OCB have a very acceptable diagnostic performance comparable to, e.g., amyloid-beta and tau proteins in Alzheimer's disease (30).

Apart from a diagnostic role OCB are of prognostic value in CIS patients with a hazard ratio of 2.18 (95\% confidence interval: 1.71-2.77) for the prediction to convert to clinically definite MS (31). A fact that has been described for conversion to MS after optic neuritis 20 years ago (32).

Given the inflammatory process, MS patients also have increased concentrations of a number of cytokines, chemokines, and interleukins in their CSF, e.g., CXCL13, IL6, IL8, and IL10 (33).

\section{CSF Findings in Other Inflammatory Demyelinating Diseases}

At first onset some symptoms are similar between MS and other inflammatory demyelinating diseases, particularly neuromyelitis optica (NMO) spectrum diseases. These syndromes can be diagnosed by IgG antibodies against AQP4 or MOG (34). In 


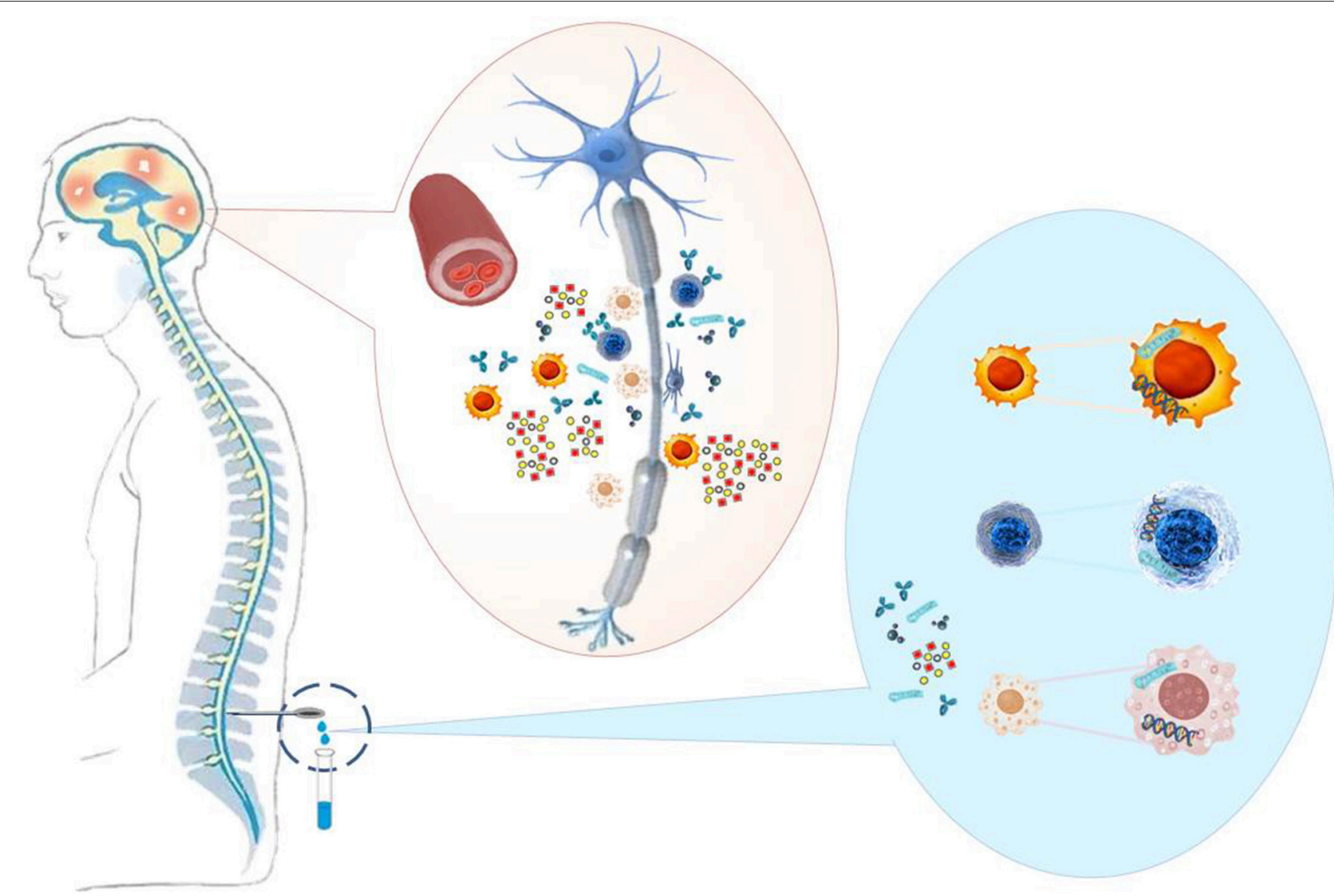

FIGURE 1 | MS causes neuronal damage (demyelination, axon degeneration, synaptic loss) to the brain and spinal cord. Immune cells, pathological antibodies, adhesion molecules, cytokines, chemokines, and nucleic acids, which reflect inflammations in the CNS, are present in the CSF of the patients and can serve as biomarkers to support MS diagnosis and therapy.

TABLE 2 | CSF changes in MS.

\begin{tabular}{ll}
\hline CSF variable & Expected finding \\
\hline $\begin{array}{l}\text { Total protein/albumin } \\
\text { quotient }\end{array}$ & Normal, rarely slightly elevated \\
CSF:serum glucose ratio & Normal \\
CSF leukocyte count & Mild pleocytosis in 50\% of patients Less than \\
& 50 cells/uL in $98 \%$ \\
Cytology & $\begin{array}{l}\text { Dominated by lymphocytes (90\%), some } \\
\text { monocytes. Rarely macrophages, plasma cells, } \\
\text { granulocytes } \\
\text { IgG concentration by linear or non-linear } \\
\text { formulae elevated in 60-70\% of patients, IgA } \\
\text { quantitative }\end{array}$ \\
and lgM synthesis may be found less frequently \\
Oligoclonal bands in 95\% of definitive MS \\
cases, $85 \%$ in CIS
\end{tabular}

general CSF work-up there is a distinct feature, which is a lack of CSF OCB in NMO spectrum diseases in $80-90 \%$ of patients (35). Total leukocyte counts in NMO spectrum disorders are similar to MS with pleocytosis being found in around $50 \%$ of patients, exceeding rarely 100 cells per uL (36). However, on differential cell counts granulocytes occur somewhat more frequently in NMO spectrum disorders compared to MS (36).

In MOG-IgG antibody associated syndromes the frequency of OCB of $13 \%$ is similarly low as in NMO spectrum disorders (37). It seems however, that CSF pleocytosis occurs more frequently, i.e., in almost two thirds of patients with a relatively high proportion of neutrophils making up 22\% of all leukocytes (37). Also, an elevated albumin quotient can be found in roughly one third of patients with MOG IgG antibodies, particularly if spinal symptoms occur.

Altogether, the main distinctive feature between these syndromes and MS is the frequency of $\mathrm{OCB}$, whereas general CSF changes (i.e., cell counts, cytology, protein) differ slightly but do not provide compelling evidence for or against one of the entities.

\section{PART II: THE RESEARCH LABORATORY Spectrum of Biomarkers in CSF}

MS is an inflammatory disease characterized by damage and repair processes. The search for biomarkers focuses not only on cells and molecules of the immune response, but also on molecules reflecting the heterogeneity of mechanisms involved 
in the disease. Many findings on potential biomarkers have been published, including antibodies, cytokines, and chemokines molecules involved in damage and repair processes, proteins of the complement system as well as nucleic acids, that could help in MS diagnosis, differential diagnosis, prognosis, and in disease or therapy monitoring. In Table 3 we listed information on various biomarkers mentioned in this article. Of these biomarkers, neurofilament light (NfL) is currently one of the most promising.

\section{CSF and Serum NfL as a Biomarker of Disease Intensity in MS}

Research over the past three decades have revealed that increased CSF concentration of the axonal injury marker NfL reflects disease activity and progression in all forms of MS (81). It has also become clear the concentrations dynamically change in response to relapses and treatment; MS patients starting natalizumab, a disease-modifying therapy (DMT) with high efficacy, experienced a normalization of their CSF NfL levels down to those seen in healthy controls within 6-12 months (82), suggesting that NfL can be used to monitor therapeutic efficacy. Similar observations have been made for fingolimod in patients with relapsing remitting (RR) MS and for mitoxantrone or rituximab and natalizumab in progressive MS (81). Recent ultrasensitive assays have made it possible to measure the biomarker in blood (serum or plasma; either matrix works fine), showing excellent correlation with CSF (99). Blood NfL behaves similar to CSF, also in response to DMTs, making it a promising blood biomarker for monitoring of treatment efficacy $(100,101)$. Ongoing studies are now also exploring it as a potential biomarker to detect side effects and suboptimal treatment efficacy. A limitation of CSF and blood NfL is that the marker is not specific to any diagnosis; it is a general marker of axonal injury and increases in all neurological disorders that involve such a process (81).

\section{Areas of Application for CSF Biomarkers Diagnosis}

For a more reliable diagnosis of MS, many studies focus on changes in CSF composition to find markers that distinguish between MS and neuronal diseases with similar symptoms. Recently, antibodies against aquaporin 4 (AQP4) were identified in CSF of NMO, but not in MS patients $(38,39)$ (Table 3). Since these antibodies are not present in every NMO patient, additional markers are needed. Another newly discovered biomarker is the anti-MOG antibody found in the CSF of patients with demyelinating diseases such as optic neuritis (usually recurrent), myelitis encephalitis, brainstem encephalitis, and acute disseminated encephalomyelitis (ADEM)-like presentations. Today, MOG-IgG-associated encephalomyelitis (MOG-EM) is considered a separate disease entity (34).Other candidates of potential biomarkers are described in the group of cytokines [e.g., interleukin (IL)-6] (39), adhesion molecules [such as soluble intracellular and vascular cell adhesion molecule (sICAM and sVCAM) (89)], damage and repair associated molecules [like glial fibrillary acidic protein (GFAP) and haptoglobin] (39) and complement components [e.g.
Complement component 1-inhibitor (C1inh), C1s, C5 and factor $\mathrm{H}]$ (94) (Table 3). Further studies need to evaluate the benefit of these molecules in diagnosis.

\section{Prognosis}

Prognostic CSF markers may influence the choice of therapy for MS, for example, when it is possible to distinguish between a very active disease course and a mild progression. Protein chitinase 3like1 (CHI3L1) and NfL are today the most promising prognostic CSF markers to predict conversion of MS on the one hand and disability on the other (58). Other markers that have been shown to have prognostic potential for predicting the conversion of CIS to clinical definite (CD) MS, from RRMS to secondary progressive (SP) MS and a worse disease progression include oligoclonal IgM bands (OCMB) and protein 14-3-3 (39).

\section{Monitoring of Therapy Response and Side Effects}

For MS various DMTs are approved by EMA and FDA. Different CSF markers are described in particular molecules of neuronal damage, pro- and anti-inflammatory cytokines and chemokines, as well as damage and repair molecules that are influenced by DMTs and that may reflect the efficacy of therapy (Table 3 ). Treatment with Natalizumab, for which most data on CSF molecules are available, leads, besides a decrease of NfL, to a downregulation of CHI3L1, neurofilament heavy (NfH), IL-6, IL8 , and chemokine (c-X-c motif) ligand CXCL13 $(33,39,82,102)$ in CSF (Table 3). CXCL13 is also downregulated in CSF of MS patients treated with steroids, B-cell depletion therapy or fingolimod $(39,59)$. CHI3L1 is down-regulated in CSF of MS patients not only by natalizumab but also by treatment with fingolimod and mitoxantrone $(39,59)$. Thus, both molecules could serve as markers for therapy-response, CXCL13 as marker of anti-inflammatory drugs and CHI3L1 for monitoring the decrease in cell damage. Recently, elevated levels of soluble cluster of differentiation (sCD) 27 and sCD21 have been found in the CSF of MS patients (95) and, in particular, sCD27 has been highlighted as a therapeutically responsive (natalizumab and methylprednisolone) potent and sensitive marker for intrathecal inflammation in progressive MS (96).

DMTs have been available for MS treatment for over 20 years and new DMTs with higher efficacy have been continuously developed since then. Depending on the mode of action of individual drugs, the risk of bacterial, viral, parasitic and/or fungal infection may increase (103). Existing latent viral infections can become active and trigger a severe infection under DMT, as the modulation of the immune system can lead to a decreased anti-viral immune response. Best known is the development of progressive multifocal leukoencephalopathy (PML) in MS patients infected with John Cunningham Virus (JCV) as a severe side effect of natalizumab therapy. Natalizumab is associated with the highest risk of PML (incidence: one in 250) of all approved MS therapies to our current knowledge (104-106). The frequency of PML increases with the duration of natalizumab and former JCVnegative patients may change to JCV-positive ones. Several cases of PML have also been reported in MS patients treated 
TABLE 3 | Selection of molecular and cellular markers and their potential utility in MS diagnosis, prognosis and monitoring.

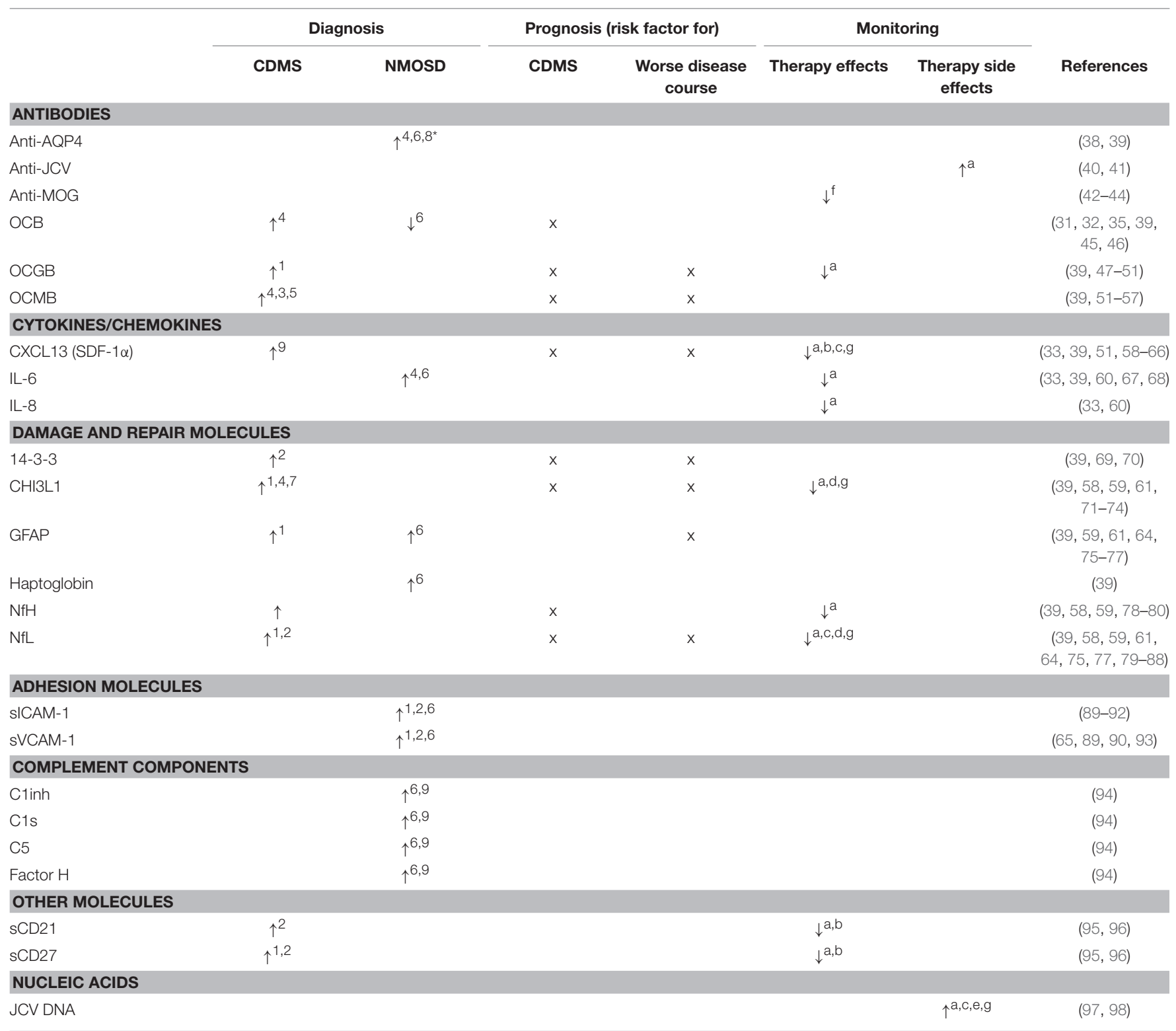

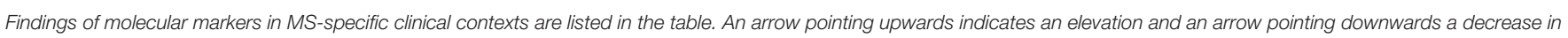

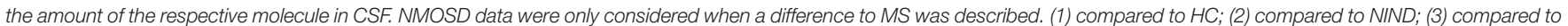

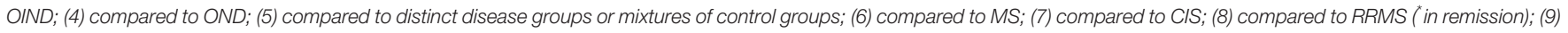

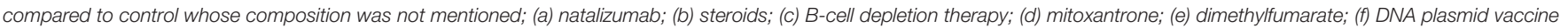
BHT-3009; (g) fingolimod.

with fingolimod or dimethylfumarate (104-106). Although there are no known cases of PML from alemtuzumab, mitoxantrone, B-cell depletion or teriflunomide in MS patients, a risk cannot be dismissed because these drugs or closely related compounds have been associated with PML in other diseases (105). The detection of JCV infection by anti-JCV indices can be prevented by B-cell depletion therapies such as Rituximab (107), since antibody production decreases with decreasing B-cell numbers. Therefore, careful monitoring of anti-JCV antibodies and/or JCV DNA in the blood and CSF is necessary, in particular for natalizumab treatment and suspected PML (108).

Not only JCV, but also other viral infections, which can even lead to encephalitis, can occur under DMTs. The risk of severe viral infections increases with cladribine (mainly herpes zoster), ocrelizumab and natalizumab (herpes), and fingolimod (herpes and varicella). Two deaths from herpes and varicella encephalitis have been reported for fingolimod (106). For this reason, careful monitoring of MS patients treated with DMTs is recommended. If virus-induced encephalitis 
is suspected, DNA analyses in the CSF may be useful for diagnosis.

\section{CONCLUSIONS}

OCB are important biomarkers that can support MRI diagnostics and help to avoid false-positive MS diagnoses. Therefore, the revised McDonalds criteria have increased the importance of the OCB.

New biomarkers such as AQP4 have now established themselves in clinical practice, and others such as Anti-MOG and NfL are about to enter clinical routine.

\section{REFERENCES}

1. Meritt HH, Fremont-Smith F, Meritt $\mathrm{HH}$, Fremont-Smith F. The Cerebrospinal Fluid. Philadelphia, PA: W. B. Saunders Company (1937).

2. Hegen H, Auer M, Zeileis A, Deisenhammer F. Upper reference limits for cerebrospinal fluid total protein and albumin quotient based on a large cohort of control patients: implications for increased clinical specificity. Clin Chem Lab Med. (2016) 54:285-92. doi: 10.1515/cclm-2015-0253

3. McCudden CR, Brooks J, Figurado P, Bourque PR. Cerebrospinal fluid total protein reference intervals derived from 20 years of patient data. Clin Chem. (2017) 63:1856-65. doi: 10.1373/clinchem.2017.278267

4. Auer M, Hegen H, Zeileis A, Deisenhammer F. Quantitation of intrathecal immunoglobulin synthesis - a new empirical formula. Eur J Neurol. (2016) 23:713-21. doi: 10.1111/ene.12924

5. Hegen H, Auer M, Deisenhammer F. Serum glucose adjusted cut-off values for normal cerebrospinal fluid/serum glucose ratio: implications for clinical practice. Clin Chem Lab Med. (2014) 52:1335-40. doi: 10.1515/cclm-2014-0077

6. Reiber H. Flow rate of cerebrospinal fluid (CSF)-a concept common to normal blood-CSF barrier function and to dysfunction in neurological diseases. J Neurol Sci. (1994) 122:189-203. doi: 10.1016/0022-510X(94)90298-4

7. Bechter K, Deisenhammer F. Psychiatric syndromes other than dementia. Handb Clin Neurol. (2017) 146:285-96. doi: 10.1016/B978-0-12-804279-3.00017-4

8. Thompson AJ, Banwell BL, Barkhof F, Carroll WM, Coetzee T, Comi G, et al. Diagnosis of multiple sclerosis: 2017 revisions of the McDonald criteria. Lancet Neurol. (2018) 17:162-73. doi: 10.1016/S1474-4422(17)30470-2

9. McDonald WI, Compston A, Edan G, Goodkin D, Hartung HP, Lublin FD, et al. Recommended diagnostic criteria for multiple sclerosis: guidelines from the International Panel on the diagnosis of multiple sclerosis. Ann Neurol. (2001) 50:121-7. doi: 10.1002/ana.1032

10. Polman CH, Reingold SC, Edan G, Filippi M, Hartung HP, Kappos L, et al. Diagnostic criteria for multiple sclerosis: 2005 revisions to the "McDonald Criteria.” Ann Neurol. (2005) 58:840-6. doi: 10.1002/ana.20703

11. Polman CH, Reingold SC, Banwell B, Clanet M, Cohen JA, Filippi M, et al. Diagnostic criteria for multiple sclerosis: 2010 revisions to the McDonald criteria. Ann Neurol. (2011) 69:292-302. doi: 10.1002/ana.22366

12. Tumani H, Deisenhammer F, Giovannoni G, Gold R, Hartung HP, Hemmer B, et al. Revised McDonald criteria: the persisting importance of cerebrospinal fluid analysis. Ann Neurol. (2011) 70:520. doi: 10.1002/ana.22508

13. Solomon AJ, Klein EP, Bourdette D. "Undiagnosing” multiple sclerosis: the challenge of misdiagnosis in MS. Neurology. (2012) 78:1986-91. doi: 10.1212/WNL.0b013e318259e1b2

14. Solomon AJ, Bourdette DN, Cross AH, Applebee A, Skidd PM, Howard DB, et al. The contemporary spectrum of multiple sclerosis misdiagnosis: a multicenter study. Neurology. (2016) 87:1393-99. doi: 10.1212/WNL.0000000000003152
An important focus in the search for new biomarkers is the monitoring of therapy efficacy and the prediction of severe side effects.

Many other CSF molecules such as CHI3L1, IL-6, or CXCL13 show potential as markers for clinical practice, but further research is needed to prove their importance.

\section{AUTHOR CONTRIBUTIONS}

All authors listed have made a substantial, direct and intellectual contribution to the work, and approved it for publication.

15. Bourahoui A, de Seze J, Guttierez R, Onraed B, Hennache B, Ferriby D, et al. CSF isoelectrofocusing in a large cohort of MS and other neurological diseases. Eur J Neurol. (2004) 11:525-9. doi: 10.1111/j.1468-1331.2004.00822.x

16. Tintore M, Rovira A, Brieva L, Grive E, Jardi R, Borras C, et al. Isolated demyelinating syndromes: comparison of CSF oligoclonal bands and different MR imaging criteria to predict conversion to CDMS. Mult Scler. (2001) 7:359-63. doi: 10.1177/135245850100700603

17. Kleinschmidt-DeMasters BK, Tyler KL. Progressive multifocal leukoencephalopathy complicating treatment with natalizumab and interferon beta-1a for multiple sclerosis. N Engl J Med. (2005) 353:369-74. doi: 10.1056/NEJMoa051782

18. Kaiser R. Variable CSF findings in early and late Lyme neuroborreliosis: a follow-up study in 47 patients. J Neurol. (1994) 242:26-36. doi: 10.1007/BF00920571

19. Freedman MS, Thompson EJ, Deisenhammer F, Giovannoni G, Grimsley G, Keir G, et al. Recommended standard of cerebrospinal fluid analysis in the diagnosis of multiple sclerosis: a consensus statement. Arch Neurol. (2005) 62:865-70. doi: 10.1001/archneur.62.6.865

20. Petzold A. Intrathecal oligoclonal IgG synthesis in multiple sclerosis. $J$ Neuroimmunol. (2013) 262:1-10. doi: 10.1016/j.jneuroim.2013.06.014

21. Standardization IO for. ISO 15189:2012 Medical laboratories Requirements for quality and competence. (2012) 3:1-53.

22. Andersson M, Alvarez-Cermeno J, Bernardi G, Cogato I, Fredman P, Frederiksen J, et al. Cerebrospinal fluid in the diagnosis of multiple sclerosis: a consensus report. J Neurol Neurosurg Psychiatry. (1994) 57:897-902. doi: 10.1136/jnnp.57.8.897

23. Deisenhammer F, Sellebjerg F, Teunissen CE, Tumani H, Deisenhammer F, Sellebjerg F, et al. Cerebrospinal Fluid in Clinical Neurology. 1st ed. Cham; New York, NY; Dordrecht; London: Springer (2015). doi: 10.1007/978-3-319-01225-4

24. Presslauer S, Milosavljevic D, Huebl W, boulenein-Djamshidian F, Krugluger W, Deisenhammer F, et al. Validation of kappa free light chains as a diagnostic biomarker in multiple sclerosis and clinically isolated syndrome: a multicenter study. Mult Scler. (2016) 22:502-10. doi: 10.1177/1352458515594044

25. Polman $\mathrm{CH}$, de Groot CJ, Koetsier JC, Sminia T, Veerman AJ. Cerebrospinal fluid cells in multiple sclerosis and other neurological diseases: an immunocytochemical study. J Neurol. (1987) 234:19-22. doi: $10.1007 / \mathrm{BF} 00314003$

26. Osenbruck M, Rao ML, Quednau HD. Pattern of albumin, immunoglobulins, and glucose in cerebrospinal fluid and serum of patients with disorders of the central nervous system. Eur Neurol. (1985) 24:16-22. doi: 10.1159/000115756

27. Hayward RA, Shapiro MF, Oye RK. Laboratory testing on cerebrospinal fluid. A reappraisal. Lancet. (1987) 1:1-4. doi: 10.1016/S0140-6736(87)92845-5

28. Link H. Immunoglobulin $\mathrm{G}$ and low molecular weight proteins in human cerebrospinal fluid. Chemical and immunological characterisation with special reference to multiple sclerosis. Acta Neurol Scand. (1967) 43:1-136. 
29. Mayringer I, Timeltaler B, Deisenhammer F. Correlation between the IgG index, oligoclonal bands in CSF, and the diagnosis of demyelinating diseases. Eur J Neurol. (2005) 12:527-30. doi: 10.1111/j.1468-1331.2005.00997.x

30. Olsson B, Lautner R, Andreasson U, Ohrfelt A, Portelius E, Bjerke M, et al. CSF and blood biomarkers for the diagnosis of Alzheimer's disease: a systematic review and meta-analysis. Lancet Neurol. (2016) 15:673-84. doi: 10.1016/S1474-4422(16)00070-3

31. Kuhle J, Disanto G, Dobson R, Adiutori R, Bianchi L, Topping $\mathrm{J}$, et al. Conversion from clinically isolated syndrome to multiple sclerosis: a large multicentre study. Mult Scler. (2015) 21:1013-24. doi: $10.1177 / 1352458514568827$

32. Soderstrom M, Ya-Ping J, Hillert J, Link H. Optic neuritis: prognosis for multiple sclerosis from MRI, CSF, and HLA findings. Neurology. (1998) 50:708-14. doi: 10.1212/WNL.50.3.708

33. Magliozzi R, Howell OW, Nicholas R, Cruciani C, Castellaro M, Romualdi $\mathrm{C}$, et al. Inflammatory intrathecal profiles and cortical damage in multiple sclerosis. Ann Neurol. (2018) 83:739-55. doi: 10.1002/ana.25197

34. Jarius S, Paul F, Aktas O, Asgari N, Dale RC, de SJ, et al. MOG encephalomyelitis: international recommendations on diagnosis and antibody testing. J Neuroinflammation. (2018) 15:134. doi: 10.1186/s12974-018-1144-2

35. Aboul-Enein F, Seifert-Held T, Mader S, Kuenz B, Lutterotti A, Rauschka H, et al. Neuromyelitis optica in Austria in 2011: to bridge the gap between neuroepidemiological research and practice in a study population of 8.4 million people. PLoS ONE. (2013) 8:e79649. doi: 10.1371/journal.pone.0079649

36. Jarius S, Paul F, Franciotta D, Ruprecht K, Ringelstein M, Bergamaschi $\mathrm{R}$, et al. Cerebrospinal fluid findings in aquaporin-4 antibody positive neuromyelitis optica: results from 211 lumbar punctures. J Neurol Sci. (2011) 306:82-90. doi: 10.1016/j.jns.2011.03.038

37. Jarius S, Ruprecht K, Kleiter I, Borisow N, Asgari N, Pitarokoili K, et al. MOG-IgG in NMO and related disorders: a multicenter study of 50 patients. Part 2: epidemiology, clinical presentation, radiological and laboratory features, treatment responses, and long-term outcome. J Neuroinflamm. (2016) 13:280. doi: 10.1186/s12974-016-0718-0

38. Long Y, Qiu W, Lu Z, Bao J, Wu A, Wang Y, et al. Aquaporin 4 antibodies in the cerebrospinal fluid are helpful in diagnosing chinese patients with neuromyelitis optica. Neuroimmunomodulation. (2012) 19:96102. doi: 10.1159/000330240

39. Matute-Blanch C, Montalban X, Comabella M. Multiple Sclerosis, and Other Demyelinating and Autoimmune Inflammatory Diseases of the Central Nervous System. 1st ed. Amsterdam: Elsevier B.V (2017).

40. Cepok S, Zhou D, Srivastava R, Nessler S, Stei S, Büssow K, et al. Identification of Epstein-Barr virus proteins as putative targets of the immune response in multiple sclerosis. J Clin Invest. (2005) 115:1352-60. doi: 10.1172/JCI23661

41. Lindsey JW, Khan U, Ansari W, Powell T, Wang YH, Guirguis MS. The antibody response to Epstein-Barr virions is altered in multiple sclerosis. $J$ Neuroimmunol. (2013) 254:146-53. doi: 10.1016/j.jneuroim.2012.09.007

42. Guggenmos J, Schubart AS, Ogg S, Andersson M, Olsson T, Mather IH, et al. Antibody cross-reactivity between myelin oligodendrocyte glycoprotein and the milk protein butyrophilin in multiple sclerosis. J Immunol. (2004) 172:661-8. doi: 10.4049/jimmunol.172.1.661

43. Hecker M, Fitzner B, Lorenz P, Flechtner K, Steinbeck F, Schröder I, et al. High-density peptide microarray analysis of igg autoantibody reactivities in serum and cerebrospinal fluid of multiple sclerosis patients. Mol Cell Proteomics. (2016) 15:1360-80. doi: 10.1074/mcp.M115.051664

44. Bar-Or A, Vollmer T, Antel J, Arnold DL, Bodner CA, Campagnolo D, et al. Induction of antigen-specific tolerance in multiple sclerosis after immunization with DNA encoding myelin basic protein in a randomized, placebo-controlled phase $1 / 2$ trial. Arch Neurol. (2007) 64:1407-15. doi: 10.1001/archneur.64.10.nct70002

45. Link H, Huang Y-MM. Oligoclonal bands in multiple sclerosis cerebrospinal fluid: an update on methodology and clinical usefulness. J Neuroimmunol. (2006) 180:17-28. doi: 10.1016/j.jneuroim.2006.07.006

46. Dobson R, Ramagopalan S, Davis A, Giovannoni G. Cerebrospinal fluid oligoclonal bands in multiple sclerosis and clinically isolated syndromes: a meta-analysis of prevalence, prognosis and effect of latitude. J Neurol Neurosurg Psychiatry. (2013) 84:909-14. doi: 10.1136/jnnp-2012-304695

47. Sellebjerg F, Jensen CV, Christiansen M. Intrathecal IgG synthesis and autoantibody-secreting cells in multiple sclerosis. J Neuroimmunol. (2000) 108:207-15. doi: 10.1016/S0165-5728(00)00292-7

48. Kasai N, Pachner AR, Yu RK. Anti-glycolipid antibodies and their immune complexes in multiple sclerosis. J Neurol Sci. (1986) 75:33-42. doi: 10.1016/0022-510X(86)90048-1

49. Nilsson P, Larsson E-M, Maly-Sundgren P, Perfekt R, SandbergWollheim M. Predicting the outcome of optic neuritis: evaluation of risk factors after 30 years of follow-up. J Neurol. (2005) 252:396-402. doi: 10.1007/s00415-005-0655-9

50. Menéndez-Valladares P, García-Sánchez MI, Martínez MA, De Veas Silva JLG, Guitarte CB, Ayuso GI. VALIDATION and meta-analysis of kappa index biomarker in multiple sclerosis diagnosis. Autoimmun Rev. (2018) 18:43-9. doi: 10.1016/j.autrev.2018.07.010

51. Gastaldi M, Zardini E, Franciotta D. An update on the use of cerebrospinal fluid analysis as a diagnostic tool in multiple sclerosis. Expert Rev Mol Diagn. (2017) 17:31-46. doi: 10.1080/14737159.2017.1262260

52. Perini P, Ranzato F, Calabrese M, Battistin L, Gallo P. Intrathecal IgM production at clinical onset correlates with a more severe disease course in multiple sclerosis. J Neurol Neurosurg Psychiatry. (2006) 77:953-5. doi: 10.1136/jnnp.2005.086116

53. Villar LM, Masjuan J, González-Porqué P, Plaza J, Sádaba MC, Roldán E, et al. Intrathecal IgM synthesis in neurologic diseases: relationship with disability in MS. Neurology. (2002) 58:824-6. doi: 10.1212/WNL.58.5.824

54. Mandrioli J, Sola P, Bedin R, Gambini M, Merelli E. A multifactorial prognostic index in multiple sclerosis: cerebrospinal fluid IgM oligoclonal bands and clinical features to predict the evolution of the disease. J Neurol. (2008) 255:1023-31. doi: 10.1007/s00415-008-0827-5

55. Villar LMM, Masjuan J, González-Porqué P, Plaza J, Sádaba MCC, Roldán E, et al. Intrathecal IgM synthesis predicts the onset of new relapses and a worse disease course in MS. Neurology. (2002) 59:555-9. doi: 10.1212/WNL.59.4.555

56. Villar LM, Masjuan J, González-Porqué P, Plaza J, Sádaba MC, Roldán E, et al. Intrathecal IgM synthesis is a prognostic factor in multiple sclerosis. Ann Neurol. (2003) 53:222-6. doi: 10.1002/ana.10441

57. Schneider R, Euler B, Rauer S. Intrathecal IgM-synthesis does not correlate with the risk of relapse in patients with a primary demyelinating event. Eur J Neurol. (2007) 14:907-11. doi: 10.1111/j.1468-1331.2007.01871.x

58. Comabella M, Sastre-Garriga J, Montalban X. Precision medicine in multiple sclerosis: biomarkers for diagnosis, prognosis, and treatment response. Curr Opin Neurol. (2016) 29:254-62. doi: 10.1097/WCO.0000000000000336

59. Lycke J, Zetterberg H. The role of blood and CSF biomarkers in the evaluation of new treatments against multiple sclerosis. Expert Rev Clin Immunol. (2017) 13:1143-53. doi: 10.1080/1744666X.2017.1400380

60. Pranzatelli MR. Advances in biomarker-guided therapy for pediatric- and adult-onset neuroinflammatory disorders: targeting chemokines/cytokines. Front Immunol. (2018) 9:557. doi: 10.3389/fimmu.2018.00557

61. Barro C, Leocani L, Leppert D, Comi G, Kappos L, Kuhle J. Fluid biomarker and electrophysiological outcome measures for progressive MS trials. Mult Scler. (2017) 23:1600-13. doi: 10.1177/1352458517732844

62. Khademi M, Kockum I, Andersson ML, Iacobaeus E, Brundin L, Sellebjerg F, et al. Cerebrospinal fluid CXCL13 in multiple sclerosis: a suggestive prognostic marker for the disease course. Mult Scler. (2011) 17:335-43. doi: $10.1177 / 1352458510389102$

63. Harris VK, Sadiq SA. Biomarkers of therapeutic response in multiple sclerosis: current status. Mol Diagn Ther. (2014) 18:605-17. doi: 10.1007/s40291-014-0117-0

64. Axelsson M, Malmeström C, Gunnarsson M, Zetterberg H, Sundström $\mathrm{P}$, Lycke $\mathrm{J}$, et al. Immunosuppressive therapy reduces axonal damage in progressive multiple sclerosis. Mult Scler. (2014) 20:43-50. doi: $10.1177 / 1352458513490544$

65. Graber JJ, Dhib-Jalbut S. Biomarkers of disease activity in multiple sclerosis. J Neurol Sci. (2011) 305:1-10. doi: 10.1016/j.jns.2011.03.026

66. Krumbholz M, Theil D, Cepok S, Hemmer B, Kivisäkk P, Ransohoff RM, et al. Chemokines in multiple sclerosis: CXCL12 and CXCL13 up-regulation is 
differentially linked to CNS immune cell recruitment. Brain. (2006) 129:20011. doi: 10.1093/brain/awh680

67. Baraczka K, Nékám K, Pozsonyi T, Szüts I, Ormos G. Investigation of cytokine (tumor necrosis factor-alpha, interleukin-6, interleukin-10) concentrations in the cerebrospinal fluid of female patients with multiple sclerosis and systemic lupus erythematosus. Eur J Neurol. (2004) 11:37-42. doi: 10.1046/j.1351-5101.2003.00706.x

68. Malmeström C, Andersson BAA, Haghighi S, Lycke J. IL-6 and CCL2 levels in CSF are associated with the clinical course of MS: implications for their possible immunopathogenic roles. J Neuroimmunol. (2006) 175:176-82. doi: 10.1016/j.jneuroim.2006.03.004

69. Bartosik-Psujek H, Archelos JJ. Tau protein and 14-3-3 are elevated in the cerebrospinal fluid of patients with multiple sclerosis and correlate with intrathecal synthesis of IgG. J Neurol. (2004) 251:414-20. doi: 10.1007/s00415-004-0336-0

70. Martínez-Yélamos A, Rovira A, Sánchez-Valle R, Martínez-Yélamos S, Tintoré M, Blanco Y, et al. CSF 14-3-3 protein assay and MRI as prognostic markers in patients with a clinically isolated syndrome suggestive of MS. $J$ Neurol. (2004) 251:1278-9. doi: 10.1007/s00415-004-0524-y

71. Correale J, Fiol M. Chitinase effects on immune cell response in neuromyelitis optica and multiple sclerosis. Mult Scler. (2011) 17:521-31. doi: $10.1177 / 1352458510392619$

72. Malmeström C, Axelsson M, Lycke J, Zetterberg H, Blennow K, Olsson B. CSF levels of YKL-40 are increased in MS and replaces with immunosuppressive treatment. J Neuroimmunol. (2014) 269:87-9. doi: 10.1016/j.jneuroim.2014.02.004

73. Comabella M, Fernández M, Martin R, Rivera-Vallvé S, Borrás E, Chiva $\mathrm{C}$, et al. Cerebrospinal fluid chitinase 3-like 1 levels are associated with conversion to multiple sclerosis. Brain. (2010) 133:1082-93. doi: 10.1093/brain/awq035

74. Stoop MP, Singh V, Stingl C, Martin R, Khademi M, Olsson T, et al. Effects of natalizumab treatment on the cerebrospinal fluid proteome of multiple sclerosis patients. J Proteome Res. (2013) 12:1101-7. doi: 10.1021/pr 3012107

75. Malmeström C, Haghighi S, Rosengren L, Andersen O, Lycke J. Neurofilament light protein and glial fibrillary acidic protein as biological markers in MS. Neurology. (2003) 61:1720-5. doi: 10.1212/01.WNL.0000098880.19793.B6

76. Axelsson M, Malmeström C, Nilsson S, Haghighi S, Rosengren L, Lycke J. Glial fibrillary acidic protein: a potential biomarker for progression in multiple sclerosis. J Neurol. (2011) 258:882-8. doi: $10.1007 / \mathrm{s} 00415-010-5863-2$

77. Avsar T, Korkmaz D, Tütüncü M, Demirci NO, Saip S, Kamasak M, et al. Protein biomarkers for multiple sclerosis: semi-quantitative analysis of cerebrospinal fluid candidate protein biomarkers in different forms of multiple sclerosis. Mult Scler. (2012) 18:1081-91. doi: $10.1177 / 1352458511433303$

78. Brettschneider J, Petzold A, Junker A, Tumani H. Axonal damage markers in the cerebrospinal fluid of patients with clinically isolated syndrome improve predicting conversion to definite multiple sclerosis. Mult Scler. (2006) 12:143-8. doi: 10.1191/135248506 ms1263oa

79. Teunissen CE, Iacobaeus E, Khademi M, Brundin L, Norgren N, Koel-Simmelink MJA, et al. Combination of CSF N-acetylaspartate and neurofilaments in multiple sclerosis. Neurology. (2009) 72:1322-9. doi: 10.1212/WNL.0b013e3181a0fe3f

80. Trentini A, Comabella M, Tintoré M, Koel-Simmelink MJA, Killestein J, Roos B, et al. N-Acetylaspartate and neurofilaments as biomarkers of axonal damage in patients with progressive forms of multiple sclerosis. J Neurol. (2014) 261:2338-43. doi: 10.1007/s00415-014-7507-4

81. Khalil M, Teunissen CE, Otto M, Piehl F, Sormani MP, Gattringer T, et al. Neurofilaments as biomarkers in neurological disorders. Nat Rev Neurol. (2018) 14:577-89. doi: 10.1038/s41582-018-0058-z

82. Gunnarsson M, Malmestrom C, Axelsson M, Sundstrom P, Dahle C, Vrethem M, et al. Axonal damage in relapsing multiple sclerosis is markedly reduced by natalizumab. Ann Neurol. (2011) 69:83-9. doi: 10.1002/ana. 22247
83. Salzer J, Svenningsson A, Sundström P. Neurofilament light as a prognostic marker in multiple sclerosis. Mult Scler. (2010) 16:287-92. doi: $10.1177 / 1352458509359725$

84. Kuhle J, Malmeström C, Axelsson M, Plattner K, Yaldizli Ö, Derfuss T, et al. Neurofilament light and heavy subunits compared as therapeutic biomarkers in multiple sclerosis. Acta Neurol Scand. (2013) 128:e33-6. doi: 10.1111/ane.12151

85. Kuhle J, Disanto G, Lorscheider J, Stites T, Chen Y, Dahlke F, et al. Fingolimod and CSF neurofilament light chain levels in relapsing-remitting multiple sclerosis. Neurology. (2015) 84:1639-43. doi: 10.1212/WNL.000000000 0001491

86. Fialová L, Bartos A, Švarcová J, Zimova D, Kotoucova J, Malbohan I. Serum and cerebrospinal fluid light neurofilaments and antibodies against them in clinically isolated syndrome and multiple sclerosis. $J$ Neuroimmunol. (2013) 262:113-20. doi: 10.1016/j.jneuroim. 2013.06.010

87. Romme Christensen J, Börnsen L, Hesse D, Krakauer M, Sørensen PS, Søndergaard HB, et al. Cellular sources of dysregulated cytokines in relapsing-remitting multiple sclerosis. J Neuroinflammation. (2012) 9:215. doi: 10.1186/1742-2094-9-215

88. Cai L, Huang J. Neurofilament light chain as a biological marker for multiple sclerosis: a meta-analysis study. Neuropsychiatr Dis Treat. (2018) 14:2241-54. doi: 10.2147/NDT.S173280

89. Uzawa A, Mori M, Masuda S, Kuwabara S. Markedly elevated soluble intercellular adhesion molecule 1 , soluble vascular cell adhesion molecule 1 levels, and blood-brain barrier breakdown in neuromyelitis optica. Arch Neurol. (2011) 68:913-7. doi: 10.1001/archneurol. 2011.148

90. Rieckmann P, Altenhofen B, Riegel A, Baudewig J, Felgenhauer K. Soluble adhesion molecules (sVCAM-1 and SICAM-1) in cerebrospinal fluid and serum correlate with MRI activity in multiple sclerosis. Ann Neurol. (1997) 41:326-33. doi: 10.1002/ana.410410307

91. Acar G, Idiman F, Kirkali G, Özakbaş S, Oktay G, Çakmakçi H, et al. Intrathecal sICAM-1 production in multiple sclerosis Correlation with triple dose Gd-DTPA MRI enhancement and IgG index. J Neurol. (2005) 252:14650. doi: $10.1007 / \mathrm{s} 00415-005-0618-1$

92. Mitosek-Szewczyk K, Stelmasiak Z, Bartosik-Psujek H, Belniak E. Impact of cladribine on soluble adhesion molecules in multiple sclerosis. Acta Neurol Scand. (2010) 122:409-13. doi: 10.1111/j.1600-0404.2010. 01330.x

93. Correale J, de los Milagros Bassani Molinas M, Bassani Molinas MDLM. Temporal variations of adhesion molecules and matrix metalloproteinases in the course of MS. $J$ Neuroimmunol. (2003) 140:198-209. doi: $10.1016 / \mathrm{S} 0165-5728(03)$ 00204-2

94. Tatomir A, Talpos-Caia A, Anselmo F, Kruszewski AM, Boodhoo D, Rus $\mathrm{V}$, et al. The complement system as a biomarker of disease activity and response to treatment in multiple sclerosis. Immunol Res. (2017) 65:1103-9. doi: 10.1007/s12026-017-8961-8

95. Komori M, Blake A, Greenwood M, Lin YC, Kosa P, Ghazali D, et al. Cerebrospinal fluid markers reveal intrathecal inflammation in progressive multiple sclerosis. Ann Neurol. (2015) 78:3-20. doi: 10.1002/ana.24408

96. Christensen JR, Komori M, Von Essen MR, Ratzer R, Börnsen L, Bielekova $\mathrm{B}$, et al. CSF inflammatory biomarkers responsive to treatment in progressive multiple sclerosis capture residual inflammation associated with axonal damage. Mult Scler. (2018) 1-10. doi: 10.1177/1352458518774880

97. Kappos L, Bates D, Edan G, Eraksoy M, Garcia-Merino A, Grigoriadis $\mathrm{N}$, et al. Natalizumab treatment for multiple sclerosis: updated recommendations for patient selection and monitoring. Lancet Neurol. (2011) 10:745-58. doi: 10.1016/S1474-4422(11)70149-1

98. Warnke C, Wattjes MP, Adams O, Hartung HP, Martin R, Weber T, et al. Progressive multifokale Leukenzephalopathie. Nervenarzt. (2016) 87:1-5. doi: 10.1007/s00115-016-0225-7

99. Gisslen M, Price RW, Andreasson U, Norgren N, Nilsson S, Hagberg L, et al. Plasma concentration of the Neurofilament Light protein (NFL) is a biomarker of CNS injury in HIV infection: a cross-sectional study. EBio Med. (2016) 3:135-40. doi: 10.1016/j.ebiom.2015.11.036 
100. Disanto G, Barro C, Benkert P, Naegelin Y, Schadelin S, Giardiello A, et al. Serum neurofilament light: a biomarker of neuronal damage in multiple sclerosis. Ann Neurol. (2017) 81:857-70. doi: 10.1002/ana.24954

101. Novakova L, Zetterberg H, Sundstrom P, Axelsson M, Khademi M, Gunnarsson $\mathrm{M}$, et al. Monitoring disease activity in multiple sclerosis using serum neurofilament light protein. Neurology. (2017) 89:2230-7. doi: 10.1212/WNL.0000000000004683

102. Axelsson M, Dubuisson N, Novakova-Nyren L, Malmeström C, Giovannoni G, Lycke J, et al. Cerebrospinal fluid NCAM levels are modulated by disease modifying therapies. Acta Neurol Scand. (2019). doi: 10.1111/ane.13069.

103. Celius EG. Infections in patients with multiple sclerosis: implications for disease-modifying therapy. Acta Neurol Scand. (2017) 136:34-6. doi: 10.1111/ane.12835

104. Bartsch T, Rempe T, Leypoldt F, Riedel C, Jansen O, Berg D, et al. The spectrum of progressive multifocal leukoencephalopathy: a practical approach. Eur J Neurol. (2019) 26:566-e41. doi: 10.1111/ene.13906

105. Berger JR. Classifying PML risk with disease modifying therapies. Mult Scler Relat Disord. (2017) 12:59-63. doi: 10.1016/j.msard.2017.01.006

106. Sedal L. Current concepts in multiple sclerosis therapy. Degener Neurol Neuromuscul Dis. (2017)7:109-25. doi: 10.2147/DNND.S1 09251
107. Baber U, Bouley A, Egnor E, Sloane JA. Anti-JC virus antibody index changes in rituximab-treated multiple sclerosis patients. J Neurol. (2018)265:2342-5. doi: 10.1007/s00415-0188996-3

108. Warnke C, Von Geldern G, Markwerth P, Dehmel T, Hoepner $\mathrm{R}$, Gold R, et al. Cerebrospinal fluid JC virus antibody index for diagnosis of natalizumab-associated progressive multifocal leukoencephalopathy. Ann Neurol. (2014) 76:792-801. doi: 10.1002/ana. 24153

Conflict of Interest Statement: The authors declare that the research was conducted in the absence of any commercial or financial relationships that could be construed as a potential conflict of interest.

Copyright (C) 2019 Deisenhammer, Zetterberg, Fitzner and Zettl. This is an openaccess article distributed under the terms of the Creative Commons Attribution License (CC BY). The use, distribution or reproduction in other forums is permitted, provided the original author(s) and the copyright owner(s) are credited and that the original publication in this journal is cited, in accordance with accepted academic practice. No use, distribution or reproduction is permitted which does not comply with these terms. 